\title{
A Review of Application and Development Trends in Ultrasonic Motors
}

\author{
Xiaoniu Li, Zhiyi Wen, Botao Jia, Teng Cao, De Yu and Dawei Wu*
}

\begin{abstract}
The structure and performance of ultrasonic motors have gradually improved with the emergence of new materials, techniques, and structural forms. Therefore, the application scope of this technology is also expanding, especially in the field of high-end equipment. This paper conducts a review of research on the application status and progress at the frontier of research on ultrasonic motors. A summary and classification of both the status of application and cutting-edge research progress are presented, including the use of ultrasonic motors in aerospace, precision, biomedical and optical engineering and the influence on ultrasonic motor design resulting from the breakthrough in advanced processing and preparation technology, structural and functional integration technology, low voltage drives and open-loop control systems. Moreover, the performance of products developed with the aid of ultrasonic motors and representative devices are compared; and state of the art ultrasonic motor designs are discussed and summarized. Finally, potential future research efforts and prospects are highlighted.
\end{abstract}

Keywords: Ultrasonic motors; applications; research progress; piezoelectric ceramics.

Received date: 26 October 2020; Accepted date: 3 December 2020.

Article type: Review article.

\section{Introduction}

Ultrasonic motors (USMs) involve the use of inverse piezoelectric effects in piezoelectric ceramic materials to generate rotation or linear motion by controlling the mechanical deformation. Recently, research and applications pertaining to such devices have rapidly advanced, such as in the area of actuation for aircrafts and detectors, cell injection based on nano-manipulation, optical scanning, and precision platform drives. ${ }^{[1-7]}$ The characteristics required include compact structure, high positional accuracy, fast response speed, and large travel range. Quick response, non-magnetic properties, high torque at low speeds, high resolution, off power self-braking, and a large working travel range are attractive characteristics for this new type of ultrasonic motor. ${ }^{[8,9]}$ Thus, variants of these devices, such as more mature, new micro-special motors, have been widely used in many engineering fields. Moreover, ultrasonic motor technology is expected to undergo new breakthroughs and development with the emergence of some new technologies, materials and configurations, such as fabrication technology for multilayer

State Key Lab of Mechanics and Control of Mechanical Structures,

Nanjing University of Aeronautics and Astronautics, Nanjing

210016, PR China.

*E-mail: dwu@nuaa.edu.cn (D. Wu) piezoelectric ceramics, micro-electro-mechanical systems (MEMS) micro-machining and 3D printing additive manufacturing technology. ${ }^{[10,11]}$

Until now, such advantages have enabled successful competition with standard electromagnetic solutions in those high-end market segments where applications require a combination of small size, high positioning accuracy, and high torque. ${ }^{[12-14]}$ Due to the lack of a deceleration mechanism in an ultrasonic motor, the overall weight is very light, the function density is high, and the structure is compact. Therefore, traditional electromagnetic motors in the application of microaircraft have gradually been replaced. Furthermore, ultrasonic motors have been increasingly used in the field of aeronautics and astronautics, where the need for stability and reliability in complex and demanding environments is very high. ${ }^{[15,16]}$ In particularly, precision driving platforms and biomedical and optical engineering all require high displacement resolution, accurate positioning, and fast response. ${ }^{[17-19]}$ Ultrasonic motors with the above characteristics have been widely developed and successfully applied in these fields. Moreover, ultrasonic motors are free of electromagnetic interference and favored in the fields of medical equipment, optical coherence tomography (OCT) imaging, magnetic resonance imaging (MRI), high-end positioning platforms and other advanced equipment. 
With the development of micro-machining technology, 3D printing technology, and the wide use of some new materials, the preparation and processing technology for ultrasonic motors have also seen a new developmental impetus, and some long standing technical problems have been solved. ${ }^{[20-22]}$ For example, 3D printing technology is employed to process irregular piezoelectric polymer composite structures to improve vibration efficiency; the insulated and lightweight nonmetallic substrate ultrasonic motors can then be developed by new materials. At the same time, the rapid development of ultrasonic motors has also brought about some progress in piezoelectric drive technology ${ }^{[23-25]}$ Structural size of the system can be significantly reduced by the construction of a structurally driven functional integrated system, which can give full play to the advantages of piezoelectric actuators. There are various demands in some fully open space actuators and robot joints. Furthermore, with the improvement in the preparation technology for multilayer piezoelectric ceramics, the low voltage drive technology of ultrasonic motors has gradually become a research hotspot. ${ }^{[26,27]}$ Recently, there have been breakthroughs in the open-loop control technology of ultrasonic motors, which carry great significance for some applications in which it is difficult to develop closed-loop control, such as cell slice actuators, ear surgical equipment, and magnetic compatible tactile interfaces. ${ }^{[28-31]}$

In this paper, application of ultrasonic motors in aerospace, optical, biomedical, and precision engineering is surveyed. Some technological breakthroughs and corresponding problems caused by new materials and technologies are then discussed. Finally, an outline for potential future work is presented.

\section{Applications of ultrasonic motors 2.1 Aerospace engineering}

Compared to electromagnetic motors, ultrasonic motors can easily function through day and night temperature differences, the effects of solar geomagnetic storms, or environments high in radiation, far more so than electromagnetic motors of the same size and power density. In addition, the ultrasonic motor structure is compact, flexible and reliable, and easy to miniaturize, which can reduce the volume of detectors and other qualities that are ideal for aircraft.

In Phase 2, Test 2 of the Defense Advanced Research
Projects Agency (DARPA)/Air Force Research Laboratory (AFRL)/National Aeronautics and Space Administration (NASA) Smart Wing program, a device was designed consisted of a flexural center and elastomeric outer skin, which was actuated by high-power traveling-wave rotary ultrasonic motors (Shinsei SPL-801). Its compact structure enabled simpler integration into the limited space available in a $30 \%$ wind tunnel model. ${ }^{[32]}$ Shinsei Corporation manufactured a variety of ultrasonic motors for different torque/speed applications during the period under consideration, as shown in Table 1.
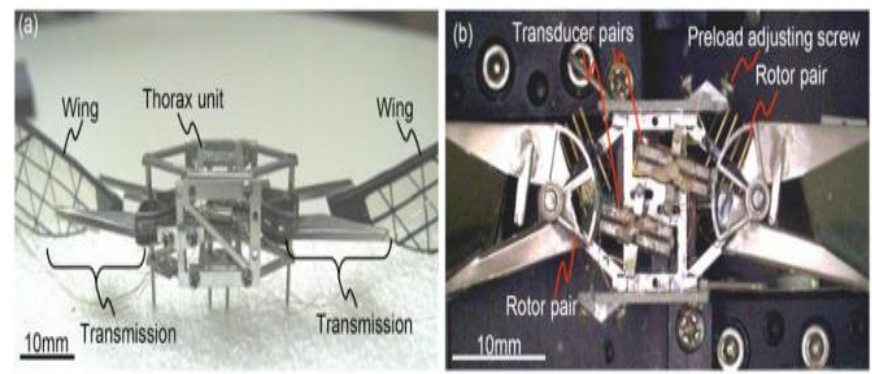

Fig. 1 Ultrasonic motor in MAV: (a) appearance of MAV; (b) inside of the MAV (Reprinted with the permission from [34], copyright Taylor \& Francis).

The Defense Advanced Research Projects Agency (DARPA) first proposed the concept of Micro Aerial Vehicles (MAV) in 1992. Based on the principle of bionics, flapping MAVs are able to achieve the optimal combination of high efficiency and flexibility. ${ }^{[33]}$ Hamamoto et al. developed a flapping MAV driven by four tiny standing-wave USMs, that weighs only $0.13 \mathrm{~g}$. The USM used the first-order longitudinal
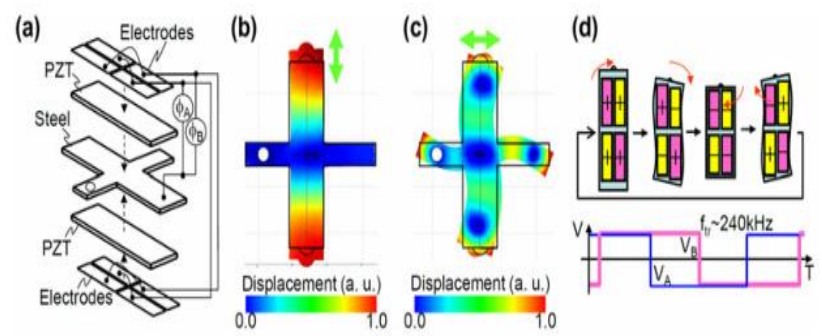

Fig. 2 Flapping MAV proposed by Hamamoto et al: (a) transducer configuration; (b) stretching vibration modes; (c) bending vibration modes; (d) control schematic voltage application (Reprinted with the permission from [35], Copyright IEEE 2015).

Table 1. Shinsei ultrasonic motor specifications.

\begin{tabular}{lcccc}
\hline Model & USR-30 & USR-45 & USR-60 & SPL-801 \\
\hline Rated torque (in.-lbs) & 0.35 & 1.5 & 3.3 & 9.375 \\
Rated speed (rpm) & 250 & 150 & 100 & 210 \\
Stall torque(in.-lbs) & 0.9 & 2.8 & 5.5 & 12.7 \\
Power output(W) & 1.0 & 2.3 & 3.9 & 23.3 \\
Weight(lbs) & 0.07 & 0.15 & 0.39 & 0.54 \\
Lifetime(h) & 1000 & 1000 & 1000 & 100 \\
Motor dimensions & 1.3 "dia $\times 0.50$ " & 2.0 "dia $\times 0.65$ " & $2.6 " \times 2.6 " \times 1$ " & $2.6 " \times 2.6 " \times 1$ " \\
\hline
\end{tabular}


vibration and the third-order bending vibration to form an elliptical motion at the tip orbit. It was employed as the actuator of a MAV despite its lower power capacity compared to the requirement for stand-alone hovering, ${ }^{[34,35]}$ as shown in Figs. 1 and 2.

USMs have been deployed in US spacecraft. For instance, the USMs used in the Micro lander for Mars were jointly developed by the Jet Propulsion Laboratory and the Massachusetts Institute of Technology. ${ }^{[36]}$ National Aeronautics and Space Administration (NASA)'s Goddar Space Flight Center in the United States has specially developed three ring-type traveling wave USMs, with diameters of 1.1, 2.5 and 2.8 in, respectively. These are used for a micro-manipulator on the space robot and have shown excellent stability and reliability. ${ }^{[37]}$

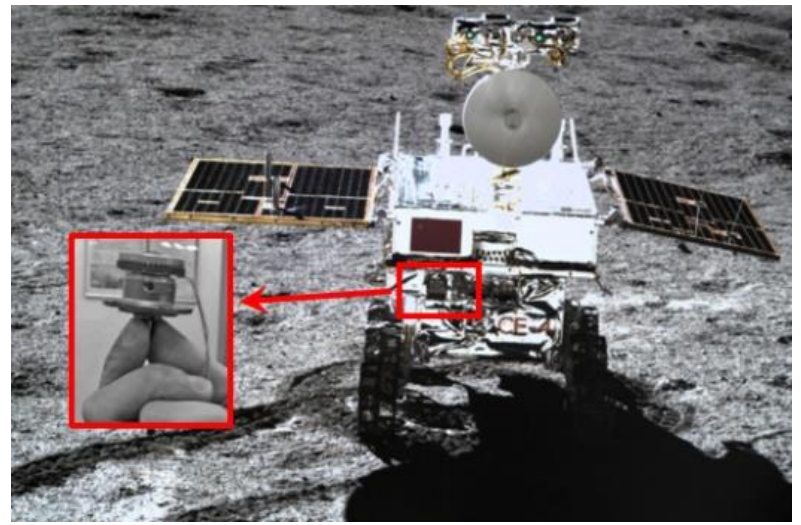

Fig. 3 USM on the lunar probe.

China Aerospace Science and Technology Corporation designed the Chang'e-3 detector and Chang'e-4 lunar probes. These vehicles reached the moon in December 2013 and January 2019, respectively. A traveling wave rotary ultrasonic motor (NUAA, PDLab) was successfully applied to two lunar probes to control the switch of their spectrometers. The motor speed reached $40 \mathrm{r} / \mathrm{min}$. The response time to the current was $1-30 \mathrm{~ms}$, the shutdown response time is $0.1-1 \mathrm{~ms}$, and the weight was only $1 / 10$ that of the traditional motor. ${ }^{[38,39]}$ The USM from the lunar probe is shown in Fig. 3.

\subsection{Precision Engineering}
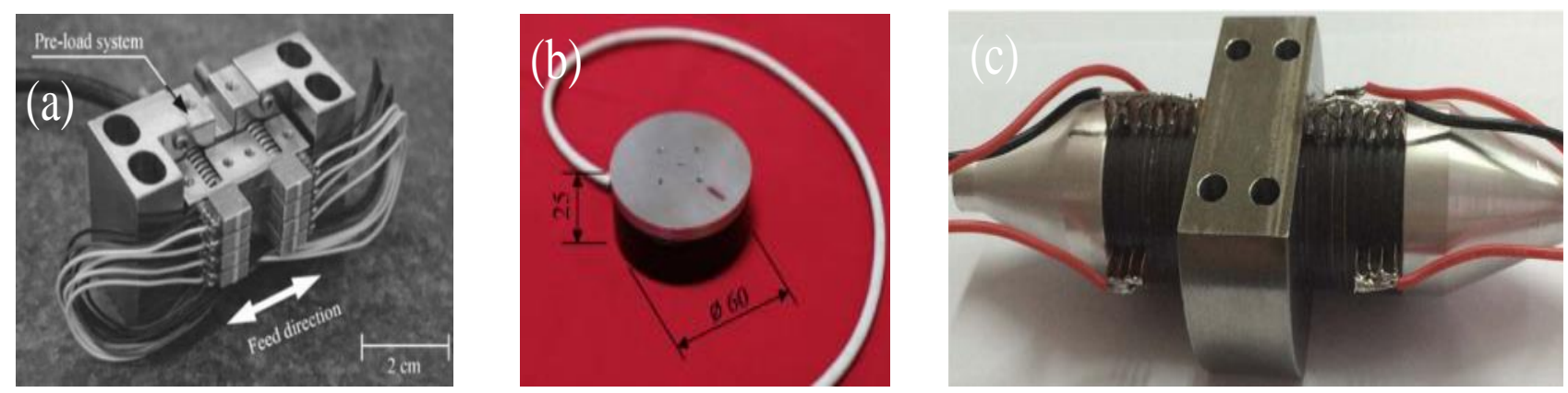

Fig. 4 The ultrasonic motors used for the precision motion stage: (a) structure of the prototype motor (reprinted with the permission from [46], Copyright 2013 IEEE); (b) structure of the micro-positioning rotary stage (reprinted with the permission from [47], copyright 2018 Elsevier); (c) structure of the proposed actuator (Reprinted with the permission from [48], copyright 2017, Elesvier). 


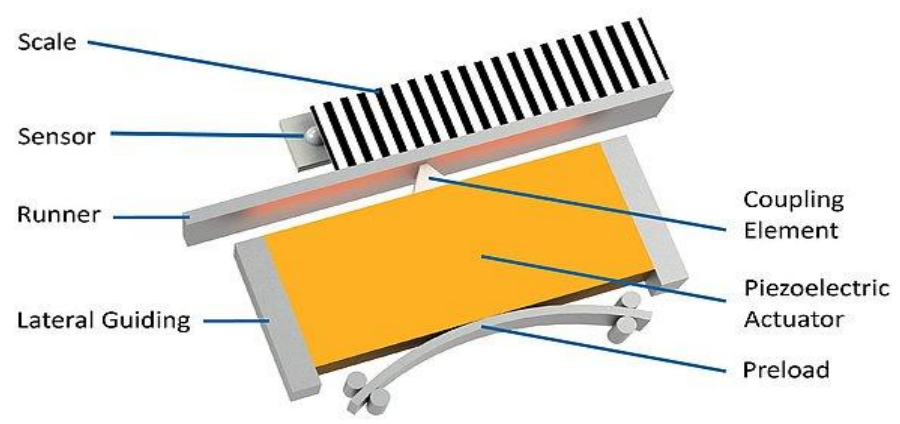

(a)

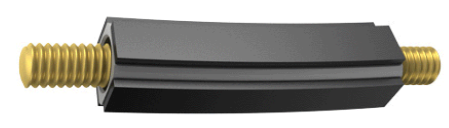

(b)

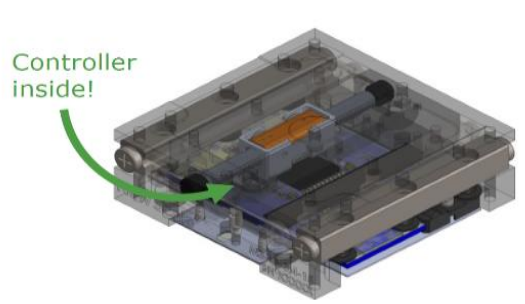

(c)

Fig. 5 The commercial ultrasonic motors used for the precision motion stage: (a) structure of PILine ${ }^{\circledR}$ Ultrasonic motors; (b) structure of the SQUIGGLE; (c) structure of the M3-LS-3.4 Linear Stage (Reprinted with the permission from [50], Copyright 2017 Elsevier).

Table 2. The specific parameters of some commercial stages.

\begin{tabular}{|c|c|c|c|c|c|c|c|}
\hline & DOF & Mode & $\begin{array}{l}\text { Size } \\
(\mathrm{mm})\end{array}$ & $\begin{array}{l}\text { Travel } \\
(\mathrm{mm})\end{array}$ & $\begin{array}{c}\text { Resolution } \\
(\mathrm{nm})\end{array}$ & $\begin{array}{l}\text { Speed } \\
(\mathrm{mm} / \mathrm{s})\end{array}$ & Output $(\mathrm{N})$ \\
\hline $\begin{array}{c}\text { B050 } \\
\text { (Nanomotion) }\end{array}$ & $X$ & $\begin{array}{l}\text { Longitudinal- } \\
\text { bending } \\
\text { compound }\end{array}$ & Width:50 & 75 & 10 & N/A & 16 \\
\hline $\begin{array}{c}\text { FB150 } \\
\text { (Nanomotion) }\end{array}$ & $\mathrm{X}$ & $\begin{array}{l}\text { Longitudinal- } \\
\text { bending } \\
\text { compound }\end{array}$ & Width: 150 & 200 & 10 & N/A & 30 \\
\hline $\begin{array}{c}\text { M3-LS-3.4-15 } \\
\text { (New Scale) }\end{array}$ & XY & $\begin{array}{l}\text { Bending } \\
\text { compound } \\
\text { vibration }\end{array}$ & $32 \times 32 \times 11$ & 15 & 500 & N/A & 1 \\
\hline $\begin{array}{c}\text { M3-LS } \\
\text { (New Scale) }\end{array}$ & $\mathrm{X}$ & $\begin{array}{l}\text { Bending } \\
\text { compound } \\
\text { vibration }\end{array}$ & $29 \times 20 \times 10$ & 6 & 500 & N/A & N/A \\
\hline $\begin{array}{c}\text { U-651.04 } \\
\text { (PI) }\end{array}$ & $\theta$ & $\begin{array}{l}\text { Compound } \\
\text { mode }\end{array}$ & N/A & $>360^{\circ}$ & $\begin{array}{c}12 \\
(\mu \mathrm{rad})\end{array}$ & $\begin{array}{l}540 \% \text { s } \\
(\operatorname{Max})\end{array}$ & N/A \\
\hline $\begin{array}{c}\mathrm{U}-521 \\
(\mathrm{PI})\end{array}$ & $X$ & $\begin{array}{l}\text { Compound } \\
\text { mode }\end{array}$ & $35 \times 35 \times 10$ & 18 & 300 & 200 & 2 \\
\hline $\begin{array}{c}\mathrm{U}-622 \\
(\mathrm{PI})\end{array}$ & $\theta$ & $\begin{array}{l}\text { Compound } \\
\text { mode }\end{array}$ & $20 \times 20 \times 10$ & $>360^{\circ}$ & $\begin{array}{c}175 \\
(\mu \mathrm{rad})\end{array}$ & $\begin{array}{l}720^{\circ} / \mathrm{s} \\
(\mathrm{Max})\end{array}$ & $5 \mathrm{mN} \cdot \mathrm{m}$ \\
\hline $\begin{array}{l}\text { U-624 } \\
(\mathrm{PI})\end{array}$ & $\theta$ & $\begin{array}{l}\text { Compound } \\
\text { mode }\end{array}$ & $30 \times 30 \times 12$ & $>360^{\circ}$ & $\begin{array}{c}35 \\
(\mu \mathrm{rad})\end{array}$ & $\begin{array}{l}720^{\circ} / \mathrm{s} \\
(\mathrm{Max})\end{array}$ & $10 \mathrm{mN} \cdot \mathrm{m}$ \\
\hline $\begin{array}{c}\text { U-651 } \\
(\mathrm{PI})\end{array}$ & $\theta$ & $\begin{array}{l}\text { Compound } \\
\text { mode }\end{array}$ & $36 \times 36 \times 14$ & $>360^{\circ}$ & $\begin{array}{c}4 \\
(\mu \mathrm{rad})\end{array}$ & $\begin{array}{l}720 \% \text { s } \\
(\operatorname{Max})\end{array}$ & $300 \mathrm{mN} \cdot \mathrm{m}$ \\
\hline $\begin{array}{l}\text { WLG-30-R } \\
\text { (Tekceleo) }\end{array}$ & $\theta$ & $\begin{array}{c}\text { Rotating } \\
\text { traveling wave }\end{array}$ & ф30 & N/A & $\begin{array}{c}785 \\
(\mu \mathrm{rad})\end{array}$ & $\begin{array}{c}1500^{\circ} / \mathrm{s} \\
(\operatorname{Max})\end{array}$ & $100 \mathrm{mN} \cdot \mathrm{m}$ \\
\hline $\begin{array}{c}\text { WLG-30-L-30 } \\
\text { (Tekceleo) }\end{array}$ & $X$ & $\begin{array}{c}\text { Compound } \\
\text { mode }\end{array}$ & $\phi 30$ & N/A & 50 & 300 & 8 \\
\hline
\end{tabular}

Nanomotion $^{[51]}$ used an ultrasonic motor coupled with bending vibration and longitudinal vibration to drive linear stages, as shown in Fig. 6(a). These stages were offered in a wide range of widths and travel lengths and can be combined in $\mathrm{X} / \mathrm{Y}$ or $\mathrm{X} / \mathrm{Y} / \mathrm{Z}$ or other multi-axis configurations. The repetitive positioning accuracy of the precision stage can reach $50 \mathrm{~nm}$. One of the typical products of the FB050 linear stage is shown in Fig. 6(b). Moreover, the specific parameters of some commercial stages are listed in Table 2.

\subsection{Biomedical Engineering}

The advantages of ultrasonic motors, such as high torque at low speed, high power density, short response time, no electromagnetic interference, and preferable performance in a 
terms of magnetic fields, make them suitable for use in the biomedical field. ${ }^{[52,53]}$ Magnetic resonance (MR) compatible devices work using a static magnetic field. Therefore, these devices should not produce electromagnetic interference while operating in the static magnetic fields. Moreover, conventional electromagnetic motors cannot be used. Nowadays, various MRI (fMRI) compatible devices are driven by ultrasonic motors because they do not in any way disturb the imaging process. ${ }^{[54-56]}$
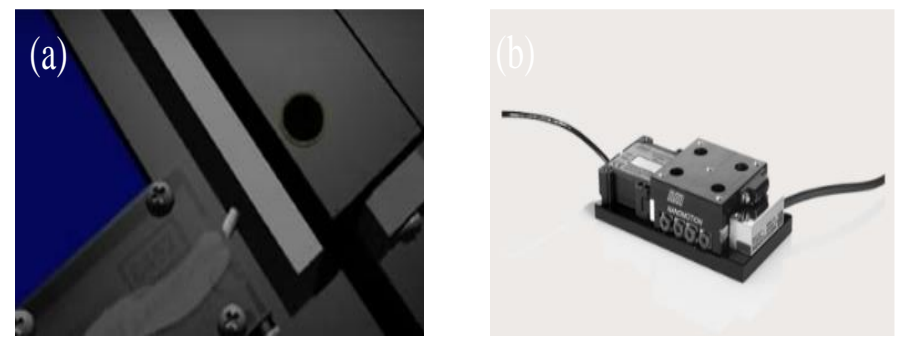

Fig. 6 Nanomotion's commercial ultrasonic motors for the precision stage: (a) USM of the precision stage; (b) FB050 Linear Stage.

Shokrollahi et al. ${ }^{[57]}$ used ultrasonic motors in an MRI device to significantly reduce geometric distortion, as shown in Fig. 7. Liu et al. [58] applied a cable transmission system actuated by ultrasonic motors to a robotic system and developed a robotic prototype manufactured with nylon to meet the MRI compatibility requirements.

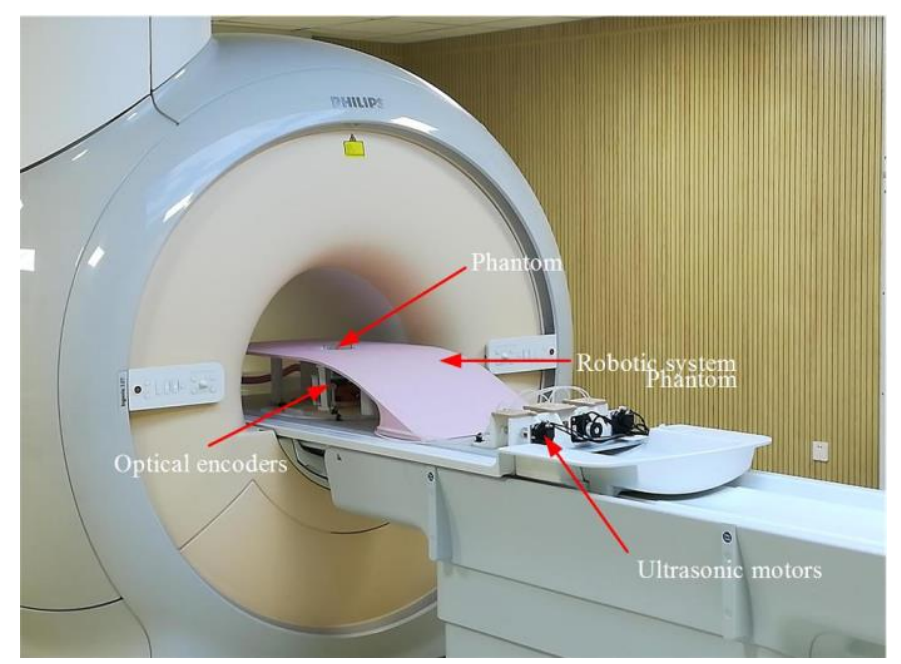

Fig. 7 Ultrasonic motors in an MRI device.

Many surgical devices have high requirements for precision and response speeds. Ultrasonic motors have been gradually applied to surgical devices due to their high precision and quick response speeds, ${ }^{[59-65]}$ as shown in Fig. 8 . For instance, a high-precision ultrasonic motor stage has been employed for a surgical ear device. ${ }^{[66,67]}$ The minimum incremental displacement of the ultrasonic is $0.3 \mu \mathrm{m}$. The maximum velocity and travel range of the USM stage are 250 $\mathrm{mm} / \mathrm{s}$ and $19 \mathrm{~mm}$, respectively. Mazurchuk et al. used the threaded rod type linear ultrasonic motor to make a flow controller with high precision, ${ }^{[68]}$ as shown in Fig. 8(b). The threaded rod type linear ultrasonic motor has a significant advantage in terms of nuclear magnetic resonance imaging (fmri) in the magnetic field strength of $4.7 \mathrm{~T}$ magnetic field environment experiments.
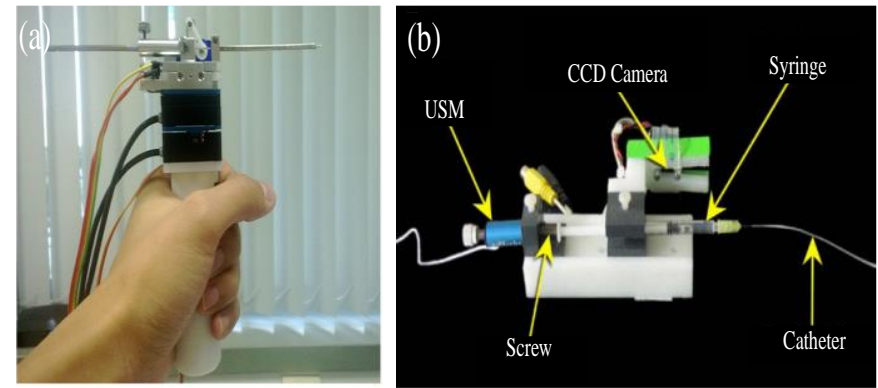

Fig. 8 Ultrasonic motors in surgical devices: (a) device for OME proposed by Tan (Reprinted with the permission from [67], Copyright 2015 American society of Mechanical Engineers); (b) ultrasonic motor-based infusion system proposed by Mazurchuk (Reprinted with the permission from [68], Copyright 2007 Elsevier).

\subsection{Optical Engineering}

Ultrasonic motors have great application potential in the photoelectric field, ${ }^{[69,70]}$ as shown in Fig. 9. For example, laserto-fiber and fiber-to-fiber alignment is a major problem in optical packaging, and must usually be solved by employing a high-precision structure and positioning system. Ultrasonic motors are highly suitable for solving these kinds of problems due to their advantages over conventional electromagnetic motors, including fast response, high precision, high power to weight ratios, no magnetic interference, and smaller package size.
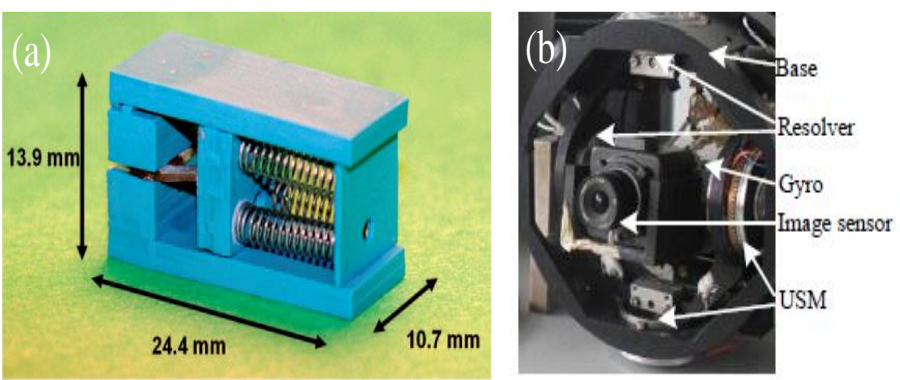

Fig. 9 (a) The prototype alignment package proposed by Park et al. (reprinted with the permission from [69], Copyright 2010 Sage Publications); (b) the Gyro stabilized platform proposed by Pan et al. (Reprinted with the Permission from [70], Copyright 2017 Elsevier).

Optical coherence tomography has very broad application prospects in the biomedical field. However, it is very difficult to manufacture micro-motors, which makes the miniaturization of probes a major challenge. Ultrasonic motors are suitable for endoscope micro-probes due to their advantageous of miniaturization, ${ }^{[71-74]}$ as shown in Fig. 10(a). Chang et al..$^{[75]}$ developed a squiggle ultrasonic motor consisting of four piezoelectric plates bonded to a threaded metal tube with a matching threaded screw shaft, as shown in Fig. 10(b). In their tests, the rotary speed was set to two 

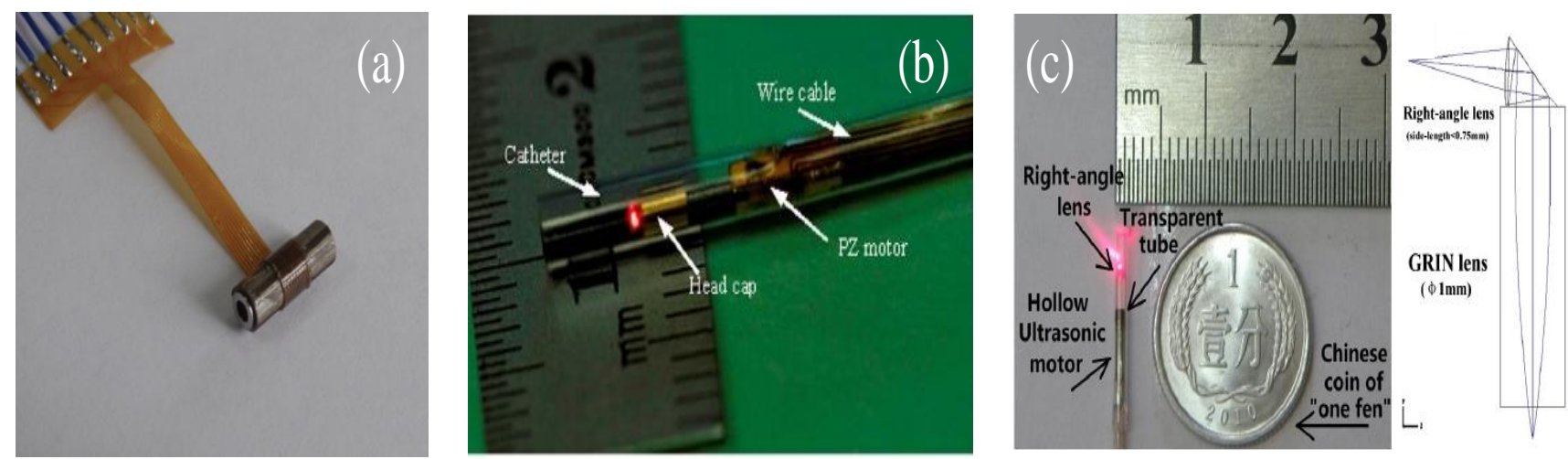

Fig. 10 (a) The stator of the ultrasonic motor proposed by Guo (reprinted with the Permission from [72], Copyright 2014 IEEE); (b)squiggle ultrasonic motor in OCT proposed by Chang (reprinted with the Permission from [75], Copyright 2011 Optical Society of America); (c) a miniaturized hollow ultrasonic motor used in an OCT proposed by Chen (reprinted with the Permission from [76], Copyright 2011 Optical Society of America).
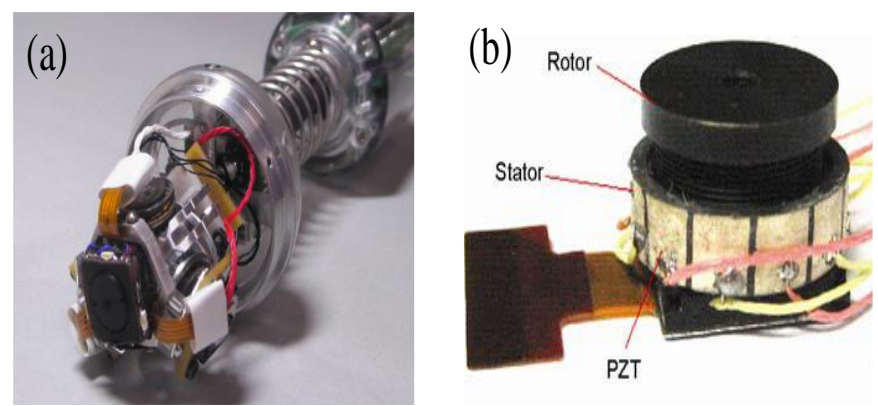

Fig. 11 (a) Pipe inspection robot with a camera, as proposed by Masahiko et al. (Reprinted with the Permission from [82], Copyright 2009 IEEE); (b) the nut-type linear ultrasonic motor proposed by Zhou et al. (Reprinted with the Permission from [83], Copyright 2009 IEEE).

cycles/s and the voltage to approximately $25 \mathrm{~V}$. Chen et al. ${ }^{[76]}$ proposed an endoscopic probe for the OCT equipped with a miniaturized hollow ultrasonic motor capable of rotating the objective lens and providing an internal channel for the fiber to pass through, thus enabling 360 degrees of unobstructed circumferential scanning, as shown in Fig. 10(c). This type of probe has an outer diameter of $1.5 \mathrm{~mm}$, which is extremely small for motorized probes with an unobstructed view in distal scanning endoscopic OCTs. Under a 7 Vrms driving voltage and a $3 \mathrm{~mA}$ current, the speed of this motor with a torque of 4 $\mu \mathrm{N} \cdot \mathrm{m}$ is $2000 \mathrm{rpm}$. Moreover, a low scanning speed of $2 \mathrm{fps}$ is achievable at $1.6 \mathrm{Vrms}$.

The ultrasonic motor also plays an essential role in the cameras. ${ }^{[77-80]}$ Masahiko et al. ${ }^{[81,82]}$ applied a spherical ultrasonic motor to the camera actuator of a pipeline inspection robot, as shown in Fig. 11(a). This design ensured that the pipe inspection detection robot could be inserted into a $50 \mathrm{~mm}$ inner diameter pipe. Zhou et al.$^{\left[{ }^{[3]}\right]}$ used a nut-type ultrasonic motor for the auto-focus module of a cellular phone, as presented in Fig. 11 (b), where the stator is shown as a nut shaped metal tube with a threaded inner surface and eight ceramic plates on the outer surface. The axial movement speed of the motor was $0.5-1 \mathrm{~mm} / \mathrm{s}$, the driving force was about 50 $\mathrm{mN}$, and the response time was less than $10 \mathrm{~ms}$.

\section{Research progress on ultrasonic motor}

\subsection{Research frontier of processing and preparation technology}

With the aim of meeting various application requirements, ultrasonic motors are evolving toward light weight, miniaturization, precision, and high efficiency. ${ }^{[84,85]}$ Ultrasonic motors with new configurations and materials are also being proposed. Moreover, the development of precision machining, micro processing, and other cutting-edge manufacturing technologies provides much convenience.
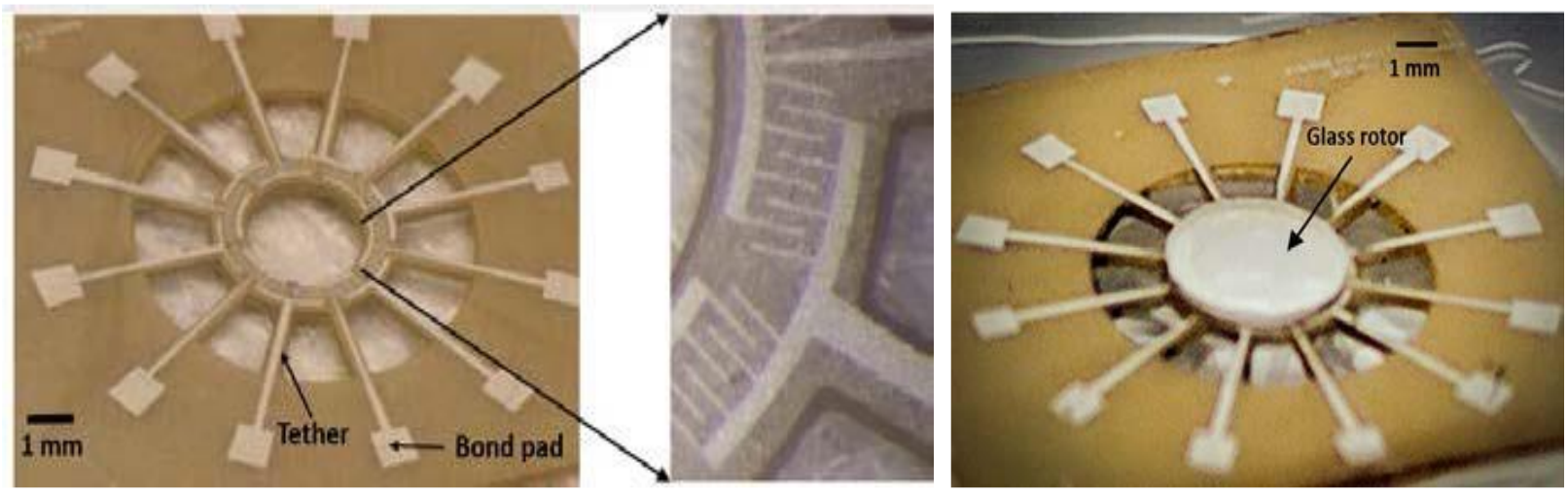

Fig. 12 Image of the transverse interdigitated electrodes used for device actuation. 
In 2018, Prakruthi Hareesh et al. ${ }^{[86]}$ presented a millimeterscale traveling wave ultrasonic rotary motor fabricated from bulk lead zirconate titanate (PZT), which is shown in Fig. 12. The motors were capable of bidirectional rotary motion with controllable speeds. Based on the micro powder blasting of homogeneous PZT sheets made by the use of single-sided transverse interdigitated electrodes, the motor stators adopted a simple manufacturing technology to drive in bending mode, the most prominent of which was the application of a normal load to increase the frictional coupling between the stator and rotor, without creating excessive drag between the rotor and other stationary components.
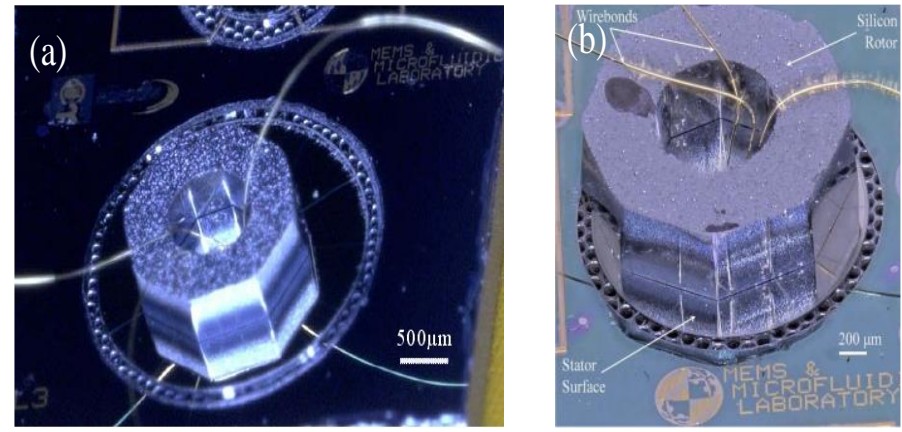

Fig. 13 (a)Rotational motion of millimeter TWUM proposed by Rudy et al. (Reprinted with the Permission from [87], Copyright 2012 IEEE); (b) high-performance rotational motion of millimeter TWUM proposed by Rudy et al. (Reprinted with the Permission from [88], Copyright 2015 IEEE).

By using a thin film lead zirconate titanate (PZT) and MEMS processing technology, Rudy et al..$^{[87]}$ put forward a rotational motion of millimeter traveling wave ultrasonic motor (TWUM) with a bidirectional control, as shown in Fig. 13(a). The direction of rotation could be shifted by switching the phase offset. The change in direction at $10 \mathrm{~V}$ of actuation (2000 rpm) was measured to occur within a space of $30 \mathrm{~ms}$. Then, the enhanced motor performance leveraged the imprint characteristics shown by the PZT thin films, which improved the speeds and caused the starting voltages to fall below $4 \mathrm{~V}$.
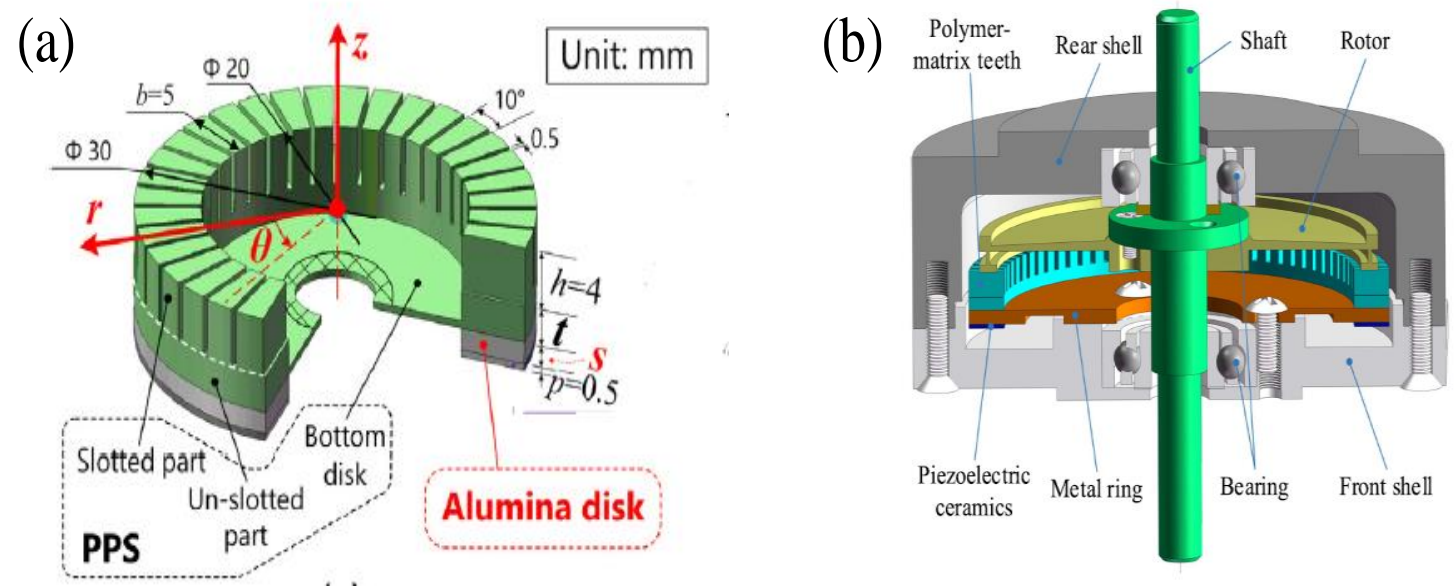

Fig. 14 (a) Traveling wave USM with PPS/alumina/PZT triple-layered stator, as proposed by Wu (Reprinted with the Permission from [90], Copyright 2018 Elsevier); (b) traveling wave USM with a metal/polymer-matrix material compound stator, as proposed by Li (Reprinted with the Permission from [95], Copyright 2020 Elsevier). 
In addition to their good physical properties, which make them available to USM, easy processing is also a property of polymers to be taken into account. It is feasible to improve the production efficiencies of USMs because their polymer vibrating bodies can be directly fabricated by molding methods instead of machining ones. Furthermore, the motors can also be made by means of 3D printing, given the lower melting point compared to metal. This can contribute to improvements in the efficiency and processing of motors with complex structures. Therefore, the motor can be better optimized to also improve the output characteristics, rather than being limited by its shape.
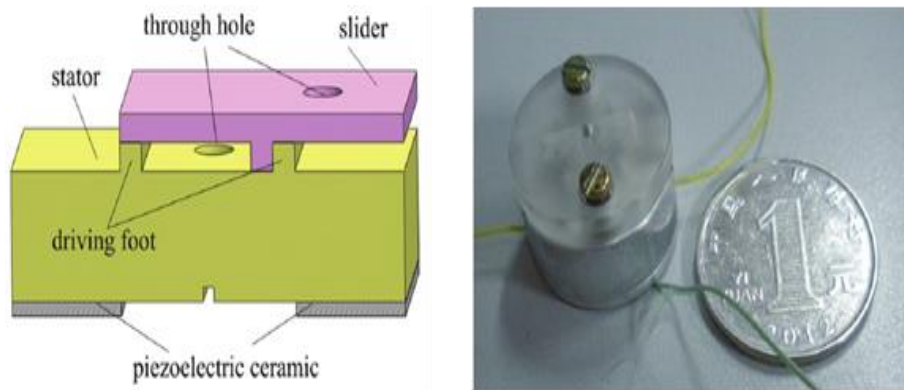

Fig. 15 Linear-type piezoelectric ultrasonic actuator for application in a Smart Fuze Safety System (SFSS).

\subsection{Integration of structure and function}

As an important branch of the piezoelectric drive field, the rapid development of ultrasonic motor technology also provides new possibilities for piezoelectric drives. USMs offer many advantages, for example, in a simple construction, a direct drive, and a brakeless and bearingless mechanism. ${ }^{[96-98]}$ These advantages contribute to the miniaturization of the structure. Among them, the integration of structure and function is an important development for piezoelectric drive technology.

Tang Y et al. ${ }^{[99]}$ presented a novel linear-type piezoelectric ultrasonic actuator for application in a Smart Fuze Safety System (SFSS), which is shown in Fig. 15. Both the slider and stator have a through hole that is used as the ignition channel of the Fuze Safety System. The initial positions of the through holes on the slider and the stator are staggered, which represents the "safety" state for the Fuze. When the through holes of the slider and stator are aligned, the Fuze is arming.

Jin et al. ${ }^{[100]}$ used the longitudinal vibration of two beams connected to the ring to excite the three-order plane traveling wave, which can combine with an actuator to drive the track movement. Two actuators make up the tracked-vehicle, as shown in Fig. 16(a). Wang et al. ${ }^{[101,102]}$ used a sandwich-type transducer to excite fourth-order in-plane traveling waves in the same direction of the ring at both ends using the longitudinal and bending vibrations of a beam, as shown in Fig. 16(b).

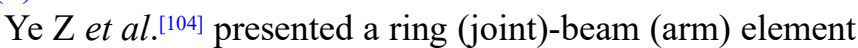
based on a piezoelectric actuator, which has a two-degree-offreedom three-arm prototype joint mechanism and is illustrated in Fig. 17(a). Chen D et al..$^{[105]}$ presented a singlemode piezoelectric actuator composed of three piezoelectric actuators articulated by two joints, as illustrated in Fig. 17(b). The size of the finger is approximately 1.5 times that of a human middle finger, and the weight is $0.11 \mathrm{~kg}$.

\subsection{Low-voltage drive and open-loop control technology for ultrasonic motors}

The application of low-voltage driving ultrasonic motor technology mostly relies on multilayer piezoelectric ceramics or MEMS processing technology. Using the Barth-type structure proposed in 1973, the American Thorlabs company took advantage of combing with multilayer piezoelectric ceramic technology to achieve success in the industrial-scale production of low-voltage driven ultrasonic motors using this structure naming it the Elliptec motor, as shown in Fig. 18. The Elliptec motor rotates forward and backward by changing the excitation frequency and using different modes of resonant housing. Due to its consistent and reliable performance, it has been widely applied in optical precision rotary positioning platforms. In particular, the entire motor requires a drive voltage of as low as $5 \mathrm{~V}$ and is capable of being integrated into a small sized circuit board. (a)

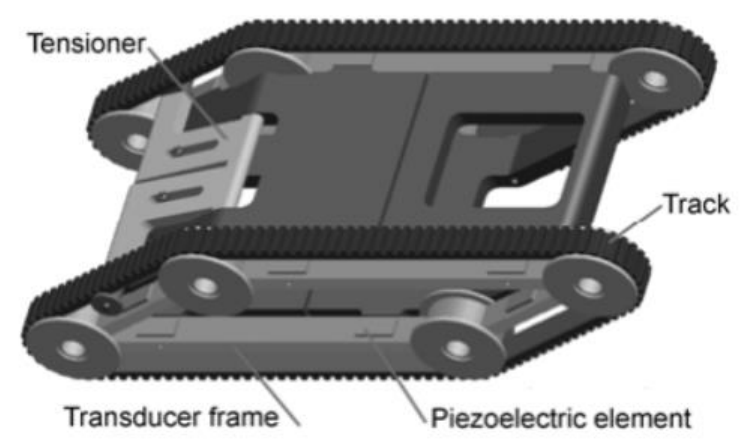

(b)

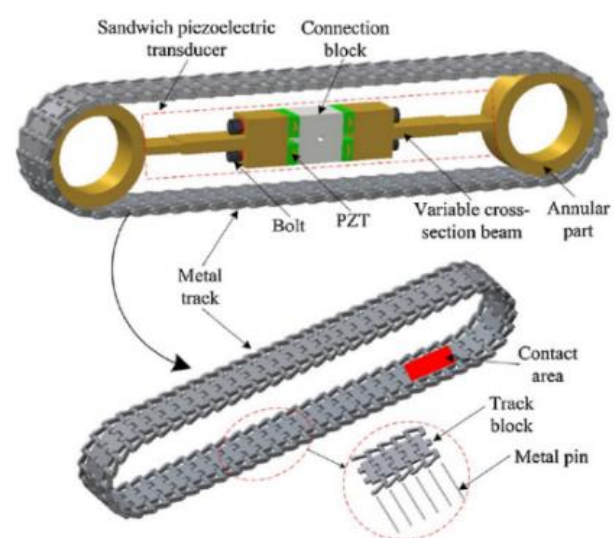

Fig. 16 (a) Tracked-vehicle structure proposed by Jin et al. (Reprinted with the Permission from [100], Copyright 2012@The Authors) (b) sandwich-type traveling wave piezoelectric tacked mobile system proposed by Wang et al. (Reprinted with the Permission from [101,102], Copyright 2016 Elsevier and 2018 Elsevier, respectively). 

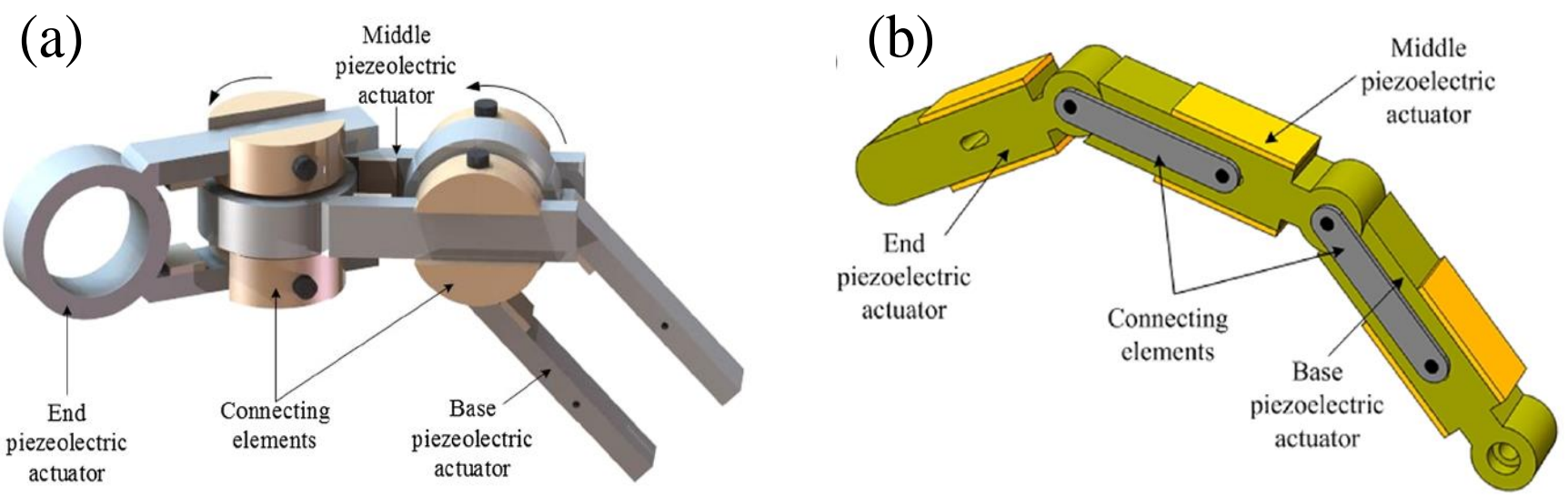

Fig. 17 (a) Ring (joint)-beam (arm) element proposed by Ye et al. (Reprinted with the Permission from [103], Copyright 2019 IOP Publishing Ltd); (b) piezoelectric actuated robotic finger at two joints proposed by Chen et al. (Reprinted with the Permission from [105], Copyright AIP Publishing).

Based on the Barth-type structure, various design schemes of rotating and linear ultrasonic motors were proposed, as shown in Fig. 19. ${ }^{[106,107]}$ Sherrit et al. applied EBM technology to design flexure horns (Ti-6Al-4V), as shown in Fig. 19(a). Unlike the Elliptec motor, this type of motor is capable of linear and rotational motion by exercising control over the horns at different positions. For example, as shown in Fig. 19(b), activating the pair of horns on the right drives the slider to the left, whereas activating the pair on the left shifts the slider to the right. As can be seen in Fig. 19(c), to drive the rotor clockwise, it is necessary to excite the horns in the top plate by driving each in resonance. Conversely, to drive the rotor counterclockwise, it is necessary to excite the horns in the bottom plate by driving each horn in resonance. Alternatively, the multilayer piezoelectric ceramics of the inactive plates can be driven with a DC voltage to reduce friction between the inactive plate and the rotor. Fig. 19(d) shows a type of motor with three orthogonal axes of rotation. In terms of design, they are applicable to such small sized systems as motors fitted in electronic cameras or small sized flight instruments. Alternatively, they could be applied to drive large structures such as the wheels of a rover or the joints of an instrument deployment device.
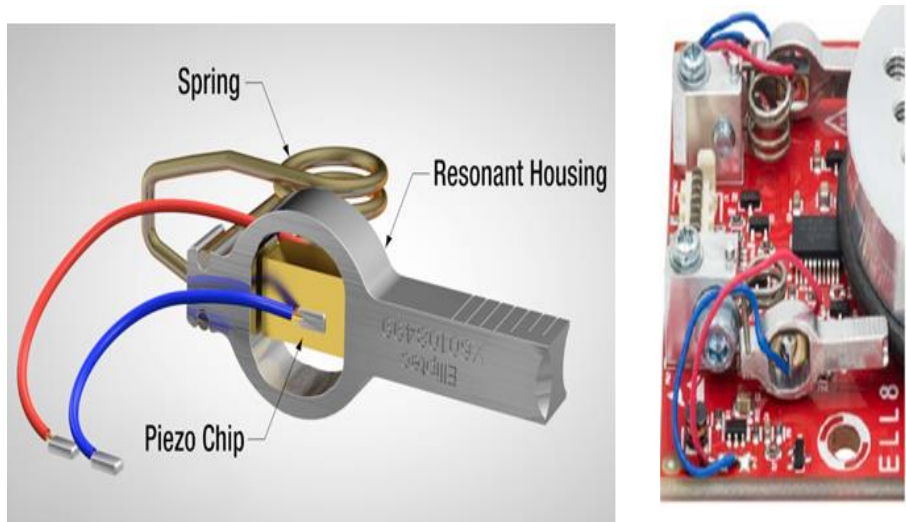

Fig. 18 Elliptec piezoelectric motor from the Thorlab company.
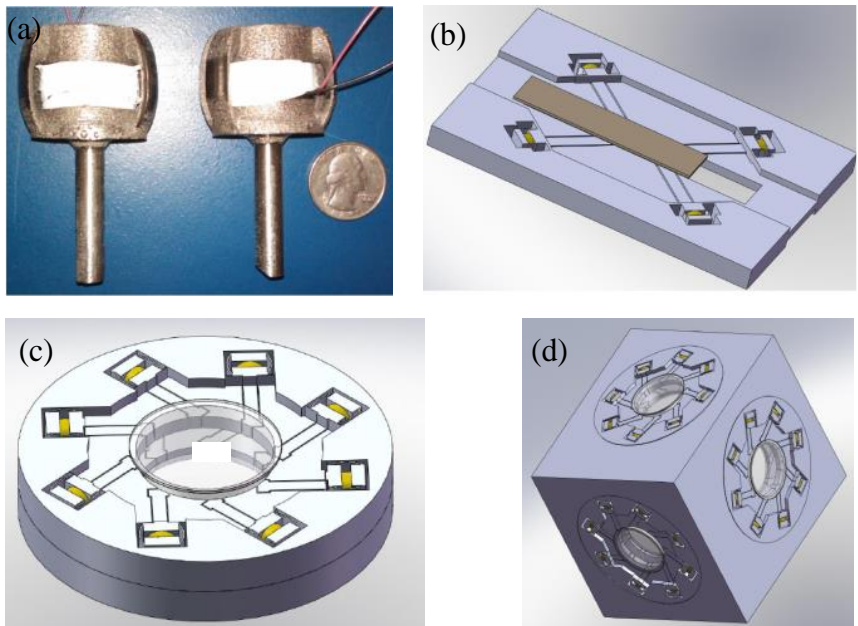

Fig. 19 Various types of motors proposed by Sherrit et al: (a) the flexure horns (Reprinted with the Permission from [106], Copyright 2010 IEEE); (b)The linear ultrasonic motor (Reprinted with the Permission from [107], Copyright 2011 Society of Photo-Optical Instrumentation Engineers (SPIE); (c) the rotating ultrasonic motor (Reprinted with the Permission from [108], Copyright 2015 Society of Photo-Optical Instrumentation Engineers (SPIE); (d) three axes of rotation ultrasonic motor (Reprinted with the Permission from [108], Copyright 2015 Society of Photo-Optical Instrumentation Engineers (SPIE).

In addition to the Barth-type structure, Yoseph BarCohen ${ }^{[108]}$ suggested a traveling wave-typed rotating ultrasonic motor driven by 12 multilayer piezoelectric ceramics and ultrasonic horns with flexures, as shown in Fig. 20(a). The vibration mode adopted by the motor could shift from the circular polarization of the single-layer piezoelectric ceramic to point excitation, thus leading to a significant reduction in the driving voltage. Furthermore, they also proposed a fourhorn rotary ultrasonic motor driven by eight multilayer piezoelectric ceramics, as shown in Fig. 20(b). Zhao Y et al. ${ }^{[109]}$ proposed an oblate-type ultrasonic standing wave micromotor with multilayer piezoelectric ceramic and chamfered driving tips, as illustrated in Fig. 21. This motor is capable of 
reaching a rotary speed of around $2000 \mathrm{r} / \mathrm{min}$ at a voltage amplitude of $20 \mathrm{Vp}-\mathrm{p}$. The ratio of the maximum displacement of the speed feeding direction to the preload direction is approximately $4: 1$, which indicates a high speed and poor ability to load.
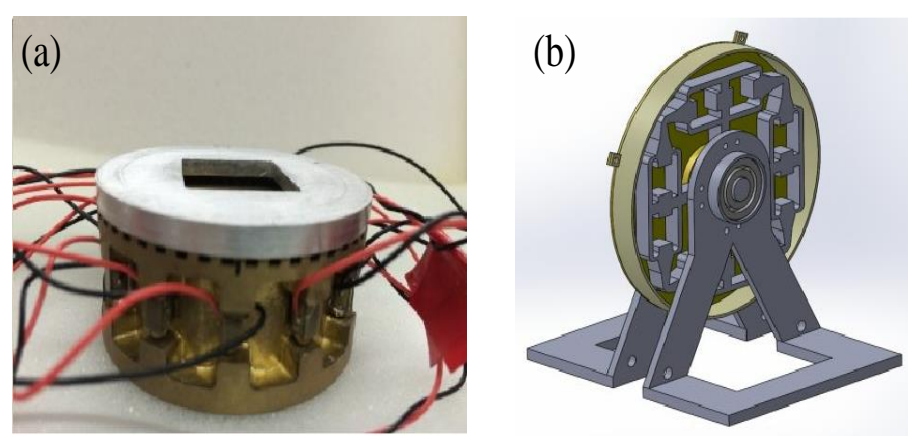

Fig. 20 (a) Traveling wave rotation; (b) four horn rotation ultrasonic motor proposed by Yosephet Reprinted with the Permission from [107], Copyright 2011 Society of Photo-Optical Instrumentation Engineers (SPIE) and (Reprinted with the Permission from [108], Copyright 2015 Society of Photo-Optical Instrumentation Engineers (SPIE)).

Despite some in-depth studies on the closed loops of ultrasonic motors, there remain many problems to be addressed in the research of open loop designs. When there is inadequate space to place precision sensors or due to the high cost of these, the analysis of open-loop stepwise motion is considered more significant, for example, cell slice actuators, ear surgical devices, and magnetic-compatible haptic interfaces make use of this. As for the unit of open-loop stepwise motion, the startup-shutdown process under varying pulse numbers must be analyzed in detail. Wang et al..$^{[110]}$ managed to obtain results when the vibration displacement in the $\mathrm{Y}$ and $\mathrm{Z}$ directions was extended with the increasing pulse numbers in finite element analysis software, as evinced by the measurement of the stepping distance. The forward and

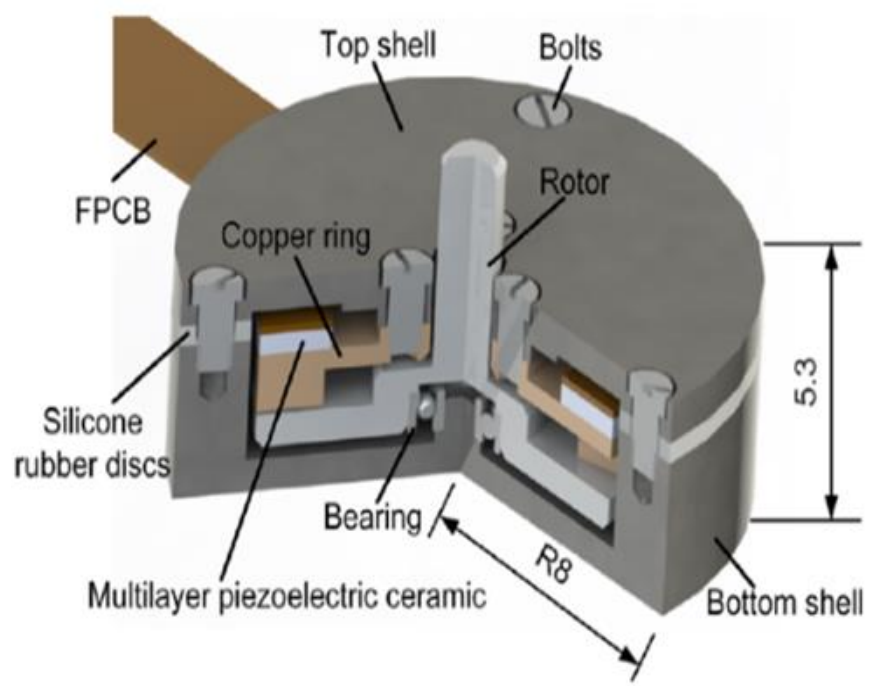

reverse displacements under different driving frequencies were then compared. However, the analysis of the interaction force revealed that the underlying mechanism was ignored. Liu et al. ${ }^{[111]}$ conducted similar research to demonstrate the positive correlation between the stepping displacement and pulse number. As was observed by Chen et al., ${ }^{[112]}$ the modal differences in the shutdown stage were associated with both amplitude and velocity at the instant of shutoff. Then, by constructing a simulation model, they determined the changes in the length of the contact and driving zone, as well as the changes in the input current, vibration state, output torque and axial pressure, based on which these rules were further explored. Finally, the velocity curves and vibration results of different impulse number functions were compared, as the stepping motion of the impulse number function with the second-order transfer function was described. Moreover, the pulse number was made optimal for the motor to achieve 3.3 $\mu$ rad both clockwise and counterclockwise.

\section{Conclusions and outlook}

The ultrasonic motor has become ever more promising with technological development, including the materials, mechanics, and manufacturing technologies. Ultrasonic motors exhibit great advantages in the fields of high-end equipment and advanced research. The applications of ultrasonic motors in aerospace, precision, biomedical, and optical engineering, especially some commercial ultrasonic motors, were reviewed in this paper. However, the extent of application of ultrasonic motors in relatively common industrial fields is far below that of the traditional electromagnetic motor. Moreover, the electromagnetic motor has also undergone considerable development in recent years, presenting both an opportunity and a challenge for the research and development of the ultrasonic motor.

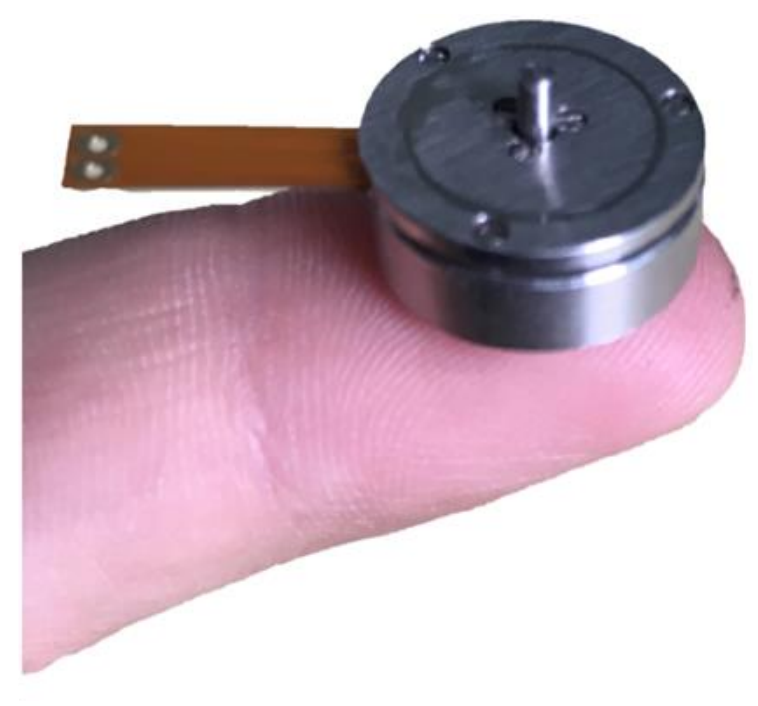

Fig. 21 Micro standing wave ultrasonic motor proposed by Zhao Y et al. (Reprinted with the Permission from [109], Copyright AIP Publishing ltd. 
The development of new materials, micro-machining and 3D printing technology has brought new technological breakthroughs for ultrasonic motors, making it possible to develop ultra-lightweight and insulating designs. This paper provides a critical review of ultrasonic motors built using polymer-based, 3D printing, or micro-machining technology. Nevertheless, this type of ultrasonic motor design exhibits some defects, such as a low electromechanical coupling coefficient, complex processing technology, limited available size, low power, severe friction, and propensity for wear.

Piezoelectric drive technology with integrated structure and functions can reduce the volume of actuators and enable new configurations to be developed. In this paper, some new configurations are introduced and potential future application trends in the future is summarized. Meanwhile, problems such as the difficulty of pre-pressure regulation, the influence of external disturbance on the drive system and the complexity of the control system are also revealed.

The rapid development of multilayer piezoelectric ceramics and micro-machining technology has great prospect for ultrasonic motors to reach large amplitudes with lowvoltage drives. Therefore, the driving voltage could be greatly reduced without compromising the performance of the ultrasonic motor, contributing to the decrease in the volume of the attached driver transformer. This would in turn have an important influence on the integration of ultrasonic motors, lightening the overall weight and enabling a real sense of no electromagnetic interference. In addition, the breakthrough in open-loop control technology for ultrasonic motors has broadened the application field of this technology and improved the displacement accuracy. In this paper, the application of micro-machining and multilayer piezoelectric ceramics technology to the ultrasonic motor is also reviewed.

\section{Conflict of Interest}

There is no conflict of interest.

\section{Supporting Information}

Not applicable

\section{References}

[1] C. Zhao, Ultrasonic motors: technologies and applications. Springer Science \& Business Media, 2011, doi: 10.1007/9783-642-15305-1.

[2] J. Xiang, Y. Yan, D. Li, Chinese J. Aeronautics, 2014, 27, 12-22, doi: 10.1016/j.cja.2013.12.009.

[3] X. Li, Z. Yao, R. Li, D. Wu, Smart Mater. Struct., 2020, 29, 025018, doi: 10.1088/1361-665X/AB627A.

[4] Y. Jian, Z. Yao, V V Silberschmidt, Ultrasonics, 2017, 77, 88-94, doi: 10.1016/J.ULTRAS.2017.01.023.

[5] R. Geng, J. K Mills, Z. Yao, Robot. Comput. Integr. Manuf., 2016, 42, 147-155, doi: 10.1016/J.RCIM.2016.06.001.

[6] T. Mashimo, S. Iduhara, S. Arai, Z. Zhang, H. Oku, IEEE Access, 2020, 8, 38546-38553, doi: 10.1109/ACCESS.2019.2957298.
[7] C. Chen, Y. Shi, J. Zhang, J. Wang, Chin. J. Mech. Eng., 2016, 29, 378-385, doi: 10.3901/CJME.2015.1216.149.

[8] B. Zhang, Z. Wang, T. Wang, Adv. Mech. Eng., 2019, 11, 1-12, doi: $10.1177 / 1687814019828582$.

[9] L. Zhang, H. Zheng, S. Huang, W. Zhang, F. Li, D. Liu, P. I. Mech. Eng. J-J. Eng., 2019, 234, 770-777, doi: $10.1177 / 1350650119871803$.

[10] L Ran, W. Zhou, J. He, L. Zhan, Q. Chen, H. Yu, B. Peng, Smart Mater. Struct., 2020, 29, 75016, doi: 10.1088/1361665X/AB87E3.

[11] L. Wang, C. Shu, J. Jin, J. Zhang, Smart Mater. Struct., 2017, 26, 035003, doi: 10.1088/1361-665X/26/3/035003.

[12] Q. Zhang, J. K. Mills, W. L. Cleghorn, J. Jin, Z. Sun, Robotica, 2015, 33, 1201-1230, doi: $10.1017 / \mathrm{S} 026357471400023 \mathrm{X}$.

[13] S. Izuhara, T. Mashimo, Sens. Actuat. A Phys., 2018, 278, 60-66, doi: 10.1016/J.SNA.2018.05.022.

[14] Y. Wang, L. Chien, Y. Jiang, K. Fu, Smart Mater. Struct., 2017, 26, 065004, doi: 10.1088/1361-665X/AA6CED.

[15] X. Li, J. Chen, Z. Chen, S. Dong, Appl. Phys. Lett., 2012, 101, 072902, doi: 10.1063/1.4747150.

[16] J. Chen, G. Liu, J. Cheng, S. Dong, Appl. Phys. Lett., 2015, 107, 032906.1-4, doi: 10.1063/1.4927328.

[17] H. Lu, W. Shang, H. Xie, Y. Shen, IEEE T. Robotics, 2018, 99, 1-11, doi: 10.1109/TRO.2017.2783937.

[18] W. Rong, S. Liang, L. Wang, IEEE-ASME T. Mech., 2017, 22, 402-411, doi: 10.1109/TMECH.2016.2597168.

[19] G. Wang, Q. Xu, IEEE-ASME T. Mech., 2017, 22, 17441754, doi: 10.1109/TMECH.2017.2698139.

[20] X. Li, Y. Yang, Y. Zhang, T. Wang, Z. Yang, Q. Wang, X. Zhang, Mater. Design, 2020, 191, 108606, doi: 10.1016/J.MATDES.2020.108606.

[21] X. Xin, Y. Yu, J. Wu, X. Gao, Z. Li, X. Yi, W. Chen, S. Don, Sensors Actuat. A Phys., 2020, 309, 112036, doi: 10.1016/J.SNA.2020.112036.

[22] H. Yokozawa, Y. Doshida, S. Kishimoto, T. Morita, Sensors Actuat. A-phys., 2018, 274, 179-183, doi: 10.1016/J.SNA.2018.02.012.

[23] C. Peng, S. Moghaddam, Dry. Technol., 2019, 38, 1-10, doi: 10.1080/07373937.2019.1596119.

[24] C. Yang, K. Xie, J. Chang, Microsys. Technol., 2020, 26, 71-78, doi: 10.1007/s00542-019-04448-6.

[25] V. Ostasevicius, V. Jurenas, I. Golinka, R. Gaidys, A. Aleksa, Actuators, 2018, 7, 14, doi: 10.3390/act7020014.

[26] H. Yu, Q. Quan, X. Tian, H. Li, Sensors, 2018, 18, 809, doi: $10.3390 / \mathrm{s} 18030809$.

[27] H. Ko, H. Jeong, B. Koc. J. Electroceram., 2009, 23, 530535, doi: 10.1007/s10832-008-9529-8.

[28] X. Dong, M. Hu, L. Jin, Z. Xu, C. Jiang, Ultrasonics, 2018, 82, 327-330, doi: 10.1016/j.ultras.2017.09.014.

[29] Z. Fang, T. Yang, Y. Zhu, S. Li, M. Yang, Sensors, 2019, 19, 5326, doi: 10.3390/s19235326.

[30] J. Shi, F. Zhao, X. Shen, X. wang, Ultrasonics, 2013, 53,1112-1123, doi: 10.1016/j.ultras.2013.02.006. 
[31] D. J. Lee, S. K. Lee, Rev. Sci. Instrum., 2015, 86, 015111, doi: $10.1063 / 1.4905897$.

[32] J. D. Bartley-Cho, D. P. Wang, C. A. Martin, J. Intell. Mater. Syst. Struct., 2004, 15, 279-291, doi: 10.1177/1045389X04042798.

[33] G. Cai, J. Dias, L. Seneviratne, UST, 2014, 2, 175-199, doi: $10.1142 / \mathrm{S} 2301385014300017$.

[34] M. Hamamoto,T. Kotani, I. Nakano, Y. Ohta, K. Hara, Y. Murakami, T. Hisada, Adv. Robot., 2014, 28, 133-144, doi: 10.1080/01691864.2013.861338.

[35] M. Hamamoto, H. Etoh, T, IEEE/RSJ IROS, 2015, doi: 10.1109/IROS.2015.7353663.

[36] H. Das, X. Bao, Y Bar-Cohen, R. Bonitz, R. A. Lindemann, M. Maimone, I. A. Nesnas, C. J. Voorhees, Smart. Mater. Struct., 1999, 3668, doi: 10.1117/12.350698.

[37] R. C. Weisbin, G. Rodriguez, P. S. Schenker, H. Das, S. A. Hayati, E. T. Baumgartner, M. Maimone, I. A. Nesnas, R. A. Volpe, Autonomous Rover Technology for Mars Sample Return. 1999, 440: 1.

[38] Z. Sun, T. Zhang, H. Zhang, Y. Jia, H. Zhang, J. Chen, X. Wu, Z. Shen, Scientia Sinica Technologica, 2014, 44, 331-343, doi: 10.1360/092014-37.

[39] W. Wu, C. Li, W. Zuo, H. Zhang, J. Liu, W. Wen, Y. Su, X. Ren, J. Yan, D. Yu, G. Dong, C. Wang, Z. Sun, E. Liu, J. Yang, Z. Ouyang, Nat. Geosci., 2019, 12, 222-223, doi: 10.1038/s41561-019-0341-7.

[40] W. L. Zhu, Z. Zhu, Y. He, K. F. Ehmann, B. F. Ju, S. Li, IEEE-ASME Trans. Mechatron., 2017, 22, 1796-1806, doi: 10.1109/TMECH.2017.2693996.

[41] C. Song, P. L. Gehlbach, J. U. Kang, Opt. Express, 2012, 20, 23414-23421, doi: 10.1364/OE.20.023414.

[42] Y. L. Yang, Y. D. Wei, J. Q. Lou, S. Fang, Smart Mater Struct., 2017, 26, 115016, doi: 10.1088/1361-665x/aa8f73.

[43] W. Yuzhang, Q. Xu, IEEE Sens. J. 2017, 17, 3975-3982, doi: 10.1109/JSEN.2017.2701835.

[44] A. J. Fleming, S. S. Aphale, S. O. Moheimani, IEEETrans. Nanotechnol., 2010, 9, 438-448, doi: 10.1109/TNANO.2009.2032418.

[45] S. Shen, P. C. Tsai, C. T. Pan, H. J. Huang, J. C. Huang, Transducers, 2011, 482-485, doi: 10.1109/TRANSDUCERS.

[46] M. Guo, J. Hu, H. Zhu, C. Zhao, S. Dong, IEEE Trans. Ultrason. Ferroelectr. Freq. Control, 2013, 60, 1446-1452, doi: 10.1109/TUFFC.2013.2716.

[47] I. Grybas, A. Bubulis, V. Jurenas, K. Ragulskis, V. Eidukynas, R. Kandrotaite Janutiene, L. Ragulskis, Precis. Eng., 2019, 361-375, doi: 10.1016/j.precisioneng.2018.10.004 [48] D. Xu, Y. Liu, J. Liu, X. Yang, W. Chen, Ceram. Int., 2017,43, S21-S26, doi: 10.1016/j.ceramint.2017.05.199.

[49] PhysikInstrumente (PI), Freiburg im Breisgau, Germany. [Online]. Available: http://www.physikinstrumente.de.

[50] New Scale Technology, New York, NY, USA. [Online]. Available: http://www.newscaletech.com.

[51] Nanomotion, New York, NY, USA. [Online]. Available: https://www.nanomotion.com.
[52] P. C. Mozer, A. W. Partin, D. Stoianovici, Reviews in urology, 2009, 11(1):7-15.

[53] G. A. Cole, K. Harrington, H. Su, et al, Springer Tracts in Advanced Robotics, 2014, 79, doi:org/10.1007/978-3-64228572-1 54.

[54] A Krieger, S Song, N B Cho, et al, IEEE-ASME Trans. Mechatron., 2013, 18, 273-284, doi: 10.1109/TMECH.2011.2163523.

[55] Song S E,Tokuda J, Tuncali K, et al. IEEE Trans. Biomed. Eng., 2013, 60, 3019-3027, doi: 10.1109/TBME.2013.2240301.

[56] Chen Y, Godage I S, Su H, et al. Ann. Biomed. Eng., 2019, 47, 335-353, doi: 10.1007/s10439-018-02158-0.

[57] Shokrollahi P, Drake J M, Goldenberg A A, et al. Biomed. journal, 2019, 42, 116-123, doi: 10.1016/j.bj.2018.12.007.

[58] W Liu, Z Yang, S Jiang, et al, Int. J. Med. Robot. Comput. Assist. Surg., 2020, 16, e2063, doi: 10.1002/rcs.2063.

[59] Liang W, Tan K K, Huang S, et al. Mechatronics, 2013, 23, 1005-1013, doi: 10.1016/j.mechatronics.2013.07.009.

[60] Zhu P, Peng H, Yang J, et al. Smart Mater. Struct., 2018, 27, doi:10.1088/1361-665X/aaad9c.

[61] J. Y. Lau, W. Liang, H. C. Liaw, et al, Asian J. Control, 2017, 20, doi:10.1002/asjc.1649.

[62] Liang W, Gao W, Tan K K. Mechatronics, 2017, 42,1-10, doi: 10.1016/j.mechatronics.2016.12.005.

[63] K. K. Tan, W. Liang, S. Huang, et al, J. Dyn. Syst. Meas. Control-Trans. ASME, 2015, 137, doi: 10.1115/1.4029409.

[64] J. Y Lau, W. Liang, K. K. Tan, et al, ISA Trans., 2019, 90, 178-188, doi: 10.1016/j.isatra.2018.12.048.

[65] S. Toyama, Appl. Mech. Mater., 2013, 332, 540-544, doi: 10.4028/www.scientific.net/AMM.332.540.

[66] K. K. Tan, W. Liang, L. P. Pham, et al, J. Med. Devices, 2014, 8, doi: 10.1115/1.4027247.

[67] P. Shokrollahi, J. M. Drake, A. A. Goldenberg. Biomed. J., 2019, 42, 116-123, doi: 10.1016/j.bj.2018.12.007.

[68] G. Steven, M. Seshadri, M. Loecher, et al, Magn. Reson. Imaging, 2008, 26, 426-432, doi: 10.1016/j.mri.2007.07.005.

[69] S. Park, A. Baker, R. Eitel, C. Randall, K. Uchino, J. Intell. Mater. Syst. Struct., 2010, 21, 469-479, doi: 10.1177/1045389X09357254.

[70] S. Pan, Sens. Actuator A-Phys., 2017, 261, 280-287, doi: 10.1016/j.sna.2017.04.048.

[71] W. Liao, T. Chen, C. Wang, et al, Opt. Lett., 2017, 42, 4040-4043, doi:10.1364/OL.42.004040.

[72] M. Guo, S. Pan, J. Hu, C. Zhao, S. Dong, IEEE Trans. Ultrason. Ferroelectr. Freq. Control, 2014, 61, 705-709, doi: 10.1109/TUFFC.2014.2958.

[73] S. Chang, E. Murdock, Y. Mao, C. Flueraru, J. Disano, Opt. Lett., 2011, 36, 4392-4394, doi:10.1364/OL.36.004392.

[74] T. Chen, N. Zhang, T. Huo, et al, J. Biomed. Opt., 2013, 18, 086011, doi: 10.1117/1.JBO.18.8.086011.

[75] K. Kim, H Park, H Kang, I. Shin, Optik, 2014, 125, 30673070, doi: 10.1016/j.ijleo.2013.12.066. 
[76] T. Zhou, Y. Chen, P. Xue, T. Liu, internaltional ultrasonics symposium, 2008, 1465-1467, doi: 10.1109/ULTSYM.2008.0356.

[77] T. Villgrattner, E. Schneider, P. Andersch, H. Ulbrich, $J$. Biomed. Opt., 2011, 5, 819-828, doi:10.1299/jsdd.5.819.

[78] D. Paik, K. Yoo, C. Kang, B. Cho, S. Nam, S. Yoon, J. Electroceram., 2009, 22, 346-351, doi: 10.1007/s10832-0089513-3.

[79] M. Hoshina, T. Mashimo, N. Fukaya, O. Matsubara, S. Toyama, Adv. Robot., 2013, 27, 199-209, doi: 10.1080/01691864.2012.754077.

[80] K. Xu, G. Jin, S. Gu, Y. Yan, Z. Sun, International Society for Optics and Photonics, 2011.

[81] F. Wang, U. Nishizawa, H. Tanaka, S. Toyama, J. Vibroeng., 2018, 20, 2939-2950, doi: 10.21595/jve.2018.20348.

[82] M. Hoshina, T. Mashimo, S. Toyama, intelligent robots and systems, 2009, 2379-2384.

[83] T. Zhou, Y. Zhang, Y. Chen, C. Lu, D. Fu, L. Hu, Sci. Bull., 2009, 54, 3778-3783, doi:10.1007/s11434-009-0593-5.

[84] C. Cheng, S. Hung, IEEE-ASME Trans. Mechatron., 2016, 21, 2197-2199, doi:10.1109/TMECH.2015.2502266.

[85] S. Izuhara, T. Mashimo, Intelligent Robots and Systems, 2018, 1-9, doi: 10.1109/IROS.2018.8594098.

[86] H. Prakruthi, D. Devoe, J. Microelectromech. Syst., 2018, 27, 547-554, doi:10.1109/JMEMS.2018.2823980.

[87] R. Rudy, D. Devoe, G. Smith, R. Polcawich, IEEE, 2012, doi: 10.1109/MAMNA.2012.6195103.

[88] R. Rudy, G. Smith, D. Devoe, R. Polcawich, J. Microelectromech. Syst., 2015, 24, 108-114, doi: 10.1109/JMEMS.2014.2317778.

[89] J. Wu, Y. Mizuno, K. Nakamura, et al, IEEE International Ultrasonics Symposium, 2014, 2514-2517, doi: 10.1109/ULTSYM.2014.0627.

[90] J. Wu, Y. Mizuno, K. Nakamura, Sens. Actuator A-Phys., 2018, 284, 158-167, doi: 10.1016/j.sna.2018.09.069.

[91] J. Wu, Y. Mizuno, M. Tabaru, K. Nakamura, Jpn. J. Appl. Phys., 2016, 55, 018001, doi: 10.7567/JJAP.55.018001.

[92] J. Wu, Y. Mizuno, K. Nakamura. Smart Mater. Struct, 2017, 26(11): 11502211, doi: 10.1088/1361-665X/aa8f71.

[93] J. Wu, Y. Mizuno, K. Nakamura. IEEE-ASME Trans. Mechatron, 2018, 23, 788-799, doi: 10.1109/TMECH.2018.2794379.

[94] T. Cao, X. Li, B. Wang, Y. Mi, G. Zhao, J. Twiefel, D. Wu, Mech. Syst. Signal Pr., 2020, 145, 106960, doi: 10.1016/j.ymssp.2020.106960.

[95] J. Li, S. Liu, N. Zhou, A. Yu, Y. Cui, P. Chen, Smart Mater. Struct., 2018, 27(1): 15027, doi: 10.1088/1361-665X/aa9cc4. [96] B. Zhang, Z. Yao, Z. Liu, X. Li, Rev. Sci. Instrum., 2018, 89, 015006, doi: 10.1063/1.5011427.

[97] Z. Wen, Q. He, G. Qiao, Rev. Sci. Instrum., 2020, 91, 055003, doi: 10.1063/1.5135956.

[98] W. Chen, X. Zhang, S. Fatikow, Rev. Sci. Instrum., 2016, 87, 115003, doi: 10.1063/1.4967218.
[99] Y. Tang, Z. Yang, X. Wang, J. Wang, Int. J. Appl. Electromagn. Mech, 2017, 53, 303-313, doi: 10.3233/JAE160044.

[100] J. Jin, F. Qian, Y. Yang, J. Zhang, K. Zhu, Chin. Sci. Bull, 2012, 57, 1339-1342, doi: 10.1007/s11434-012-5004-7.

[101] L. Wang, C. Shu, Q. Zhang, J. Jin, Ultrasonics, 2017, 75, 28-35, doi: 10.1016/j.ultras.2016.11.006.

[102] L. Wang, C. Xue, V. Hofmann, F. Bai, J. Jin, J. Twiefel, Mech. Syst. Signal Pr., 2019, 122, 171-191, doi: 10.1016/j.ymssp.2018.12.014.

[103] P. Yu, L. Wang, J. Jin, Z. Ye, D. Chen, Smart Mater. Struct., 2019, 28, 105047, doi: 10.1088/1361-665X/ab3c3a.

[104] Z. Ye, C. Zhou, J. Jin, P. Yu, F. Wang, Ultrasonics, 2019, 90-95, doi: 10.1016/j.ultras.2019.02.007.

[105] D. Chen, Li. X, J. Jin, C. Ruan, Rev. Sci. Instrum., 2019, 90, 015003.

[106] S. Sherrit, X. Bao, M. Badescu, Y. Bar-Cohen, internaltional ultrasonics symposium, 2010, 886-889, doi: 10.1109/ULTSYM.2010.5935440.

[107] S. Sherrit, X. Bao, M. Badescu, Z. Chang, D. Geiyer, P. Allen, P. Ostlund, Y. Bar-Cohen, Proc. SPIE, 2011, 20, doi: 10.1117/12.880496

[108] Y. Barcohen, S. Sherrit, X. Bao, M. Badescu. S. Lih, Proc. SPIE, 2015, 9433, 943302, doi: 10.1117/12.2084543.

[109] Y. Zhao, X. Chu, C. Zhu, S. Yuan, S. Gao, Rev. Sci. Instrum., 2016, 87, 095108, doi: 10.1063/1.4963662.

[110] L. Wang, Y. Liu, K. Li, S. Chen, X. Tian, Sens. Actuator A-Phys, 2019, 285, 182-189, doi: 10.1016/j.sna.2018.11.018.

[111] J. Liu, Y. Liu, L. Zhao, D. Xu, W. Chen, IEEE Trans. Ind. Electron., 2018, $\quad \mathbf{6 5}, \quad 8063-8071, \quad$ doi: 10.1109/TIE.2018.2798627

[112] N. Chen, J. Zheng, X. Jiang, S. Fan, D. Fan, Front. Mech. Eng., 2020, 15, 585-599, doi: 10.1007/s11465-019-0577-3.

\section{Author information}

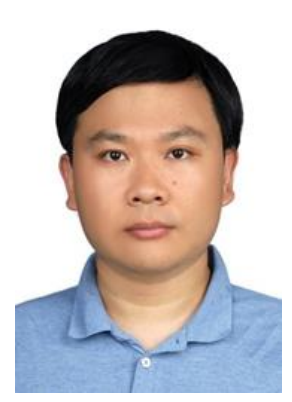

Xiaoniu $\mathbf{L i}$ received the B.S. degree in mechanical engineering from Linyi University, Linyi, China, the M.S. degree in instrument science and technology from Nanjing University of Aeronautics and Astronautics, Nanjing, China, and the Ph.D. degree in engineering mechanics from Nanjing University of Aeronautics and Astronautics, in 2009, 2013, and 2018, respectively. Currently, he is working as a Lecturer with the College of Aerospace Engineering of the Nanjing University of Aeronautics and Astronautics, Nanjing, China. His research interests include dynamic analysis, vibration control and the technology of ultrasonic motors. 


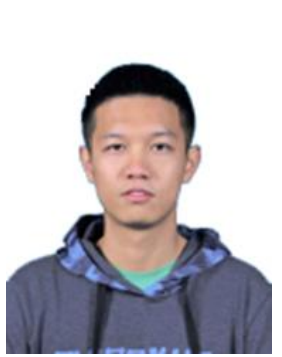

Zhiyi Wen received the B.S. degree in printing engineering from Nanjing Forestry University, Nanjing, China, the M.S. degree in mechanical engineering from Liaoning University of Technology, Jinzhou, China, in 2016 and 2020, respectively. Currently, he is working as a research assistant with the College of the Nanjing University of Aeronautics and Astronautics, Nanjing, China. His research interests include vibration application engineering, Piezoelectric actuator technology, and the technology of ultrasonic motors.

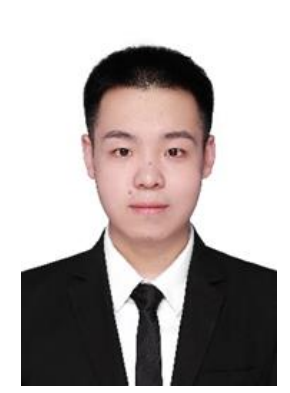

Botao Jia received his B.E. degree in aircraft design and engineering from Nanjing University of Aeronautics and Astronautics, Nanjing, China, in 2019. He is currently pursuing the master's degree in mechanical design and theory from Nanjing University of Aeronautics and Astronautics. His research interests include design, modeling, and control of piezoelectric actuators.

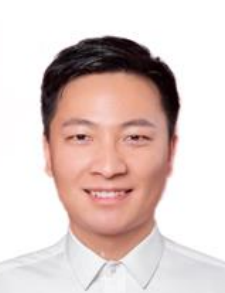

Teng Cao received the B.S. degree in mechanical design, manufacturing and automation from Zaozhuang University, Zaozhuang, China, in 2014, the M.S. degree in mechanical engineering from Nanchang Hangkong University, Nanchang, China, in 2018. Currently, he is a Ph.D candidate at Nanjing University of Aeronautics and Astronautics, Nanjing, China. His research interests include piezoelectric actuator.

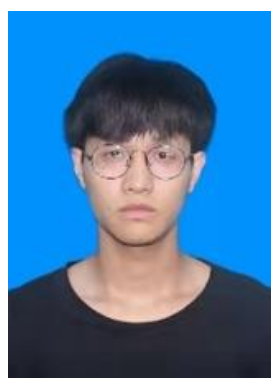

De $Y u$ received the B.S. degree in mechanical design and manufacture and automation from Wuhan Institute of Technology, Wuhan, China. Currently, he is a postgraduate student at Nanjing University of Aeronautics and Astronautics, Nanjing, China. His research interests include dynamic analysis, technology and $3 D$ printing of

ultrasonic motors.

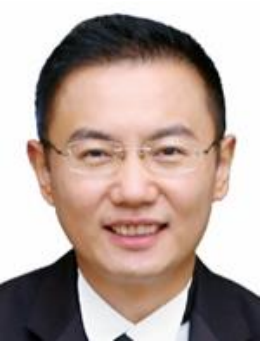

Dawei Wu (M'14) received the B.S. degree from Shanghai Jiao Tong University, Shanghai, China, in 1999, the M.S. degree from the University of Miami, Coral Gables, FL, USA, in 2004, and the Ph.D. degree from the University of Southern California, Los Angeles, CA, USA, in 2009, all in biomedical engineering. He is currently working as a Professor with the State Key of Mechanics and Control of Mechanical Structures of the Nanjing University of Aeronautics and Astronautics, Nanjing, China. He has authored and coauthored more than 50 research papers. He is currently the Deputy Editor-inChief of the Journal of Vibration, Measurement and Diagnosis. His research interests include high frequency ultrasound and miniature ultrasonic devices technologies and their applications.

Publisher's Note Engineered Science Publisher remains neutral with regard to jurisdictional claims in published maps and institutional affiliations. 